Research Article

\title{
Evaluation of Coordination and Coupling Degree of Cross-Regional Influence of the Construction Industry Based on Regional Economic Factors: A Case Study of Beijing, Capital of China
}

\author{
Likun Zhao $\mathbb{D}^{1},{ }^{1}$ Yanqi Liu $\mathbb{D}^{1},{ }^{1}$ Liwen Chen $\mathbb{D}^{2},{ }^{2}$ and Junsen Tian $\mathbb{D}^{1}$ \\ ${ }^{1}$ School of Civil Engineering, North China University of Technology, Beijing 100144, China \\ ${ }^{2}$ School of Economics and Management, Hebei University of Technology, Tianjin300401, China \\ Correspondence should be addressed to Liwen Chen; lwchen@hebut.edu.cn
}

Received 24 December 2020; Accepted 7 August 2021; Published 30 September 2021

Academic Editor: Ruguo Fan

Copyright (c) 2021 Likun Zhao et al. This is an open access article distributed under the Creative Commons Attribution License, which permits unrestricted use, distribution, and reproduction in any medium, provided the original work is properly cited.

\begin{abstract}
Taking Beijing as the core, this study takes the data related to the construction industry from 2011 to 2018 as the basis. By constructing a cross-regional influence model and collaborative coupling evaluation model of China's construction industry considering economic, social, and ecological development, this study comprehensively investigates the current situation of the cross-regional development of China's capital construction industry. Results show that the external contribution of Beijing's construction industry is manifested in three situations. A general trend of rising first and then falling is also observed. The contribution of Beijing's construction enterprises to northwest China has long been low, whereas its contribution rate to Tianjin, Hebei, and Guangdong Provinces is high. The regional difference is significant, showing a "catch-up effect." The contribution degree and the development level of China's construction industry are usually at a low coupling and antagonistic level. The verification of the influencing factors indicates that the external influence of the construction industry in Beijing has a significant positive effect on the supporting environment of the industry and the development level of the construction industry.
\end{abstract}

\section{Introduction}

With the process of China's economic transformation and structural adjustment [1], the trend of industrial transfer is becoming increasingly evident. Cross-regional and transnational transfer of China's construction industry has become a common phenomenon. With a strong degree of outward orientation, a city's industry will constantly provide products and services to other regions, stimulate its own economic diversification and intensification, and thus gain greater development potential and space.

In February 2014, General Secretary Jinping Xi determined the new strategic position of Beijing, that is, to adhere to and strengthen the "four centers" of the capital city. Those functions that do not conform to the four strategic positioning of the capital city and affect the effective play of the capital's functions are noncapital functions, which will be sorted out in an orderly manner through the principle of "controlling the increment and depleting the stock."

Liu and Qiao [2] comparatively analyzed indicators such as the mobility and entry barriers of the construction industry in Beijing, Tianjin, and Hebei, and the results showed that Beijing's construction market is highly outward oriented and "actively export oriented." The study of Xue and Chen [3] showed that the adjustment of labor force does not necessarily have a positive effect on key development industries, and the construction industry has suffered the greatest impact.

Tian and Wang [4] found that the construction industry should strengthen international market development and increase its share in the international contracting market. This suggestion not only can expand the survival and development space of China's construction enterprises but also 
help learn the advanced experience of the construction industry of developed countries and enhance China's comprehensive competitiveness in the international construction market.

At present, the construction industry in Beijing is still in the extensive labor-intensive stage. In the process of building construction and demolition, more greenhouse gases are produced, and the proportion of energy consumption reaches $1.281 \%$, which is not in line with the strategic positioning of the capital city. Beijing has taken relevant measures, such as transfer of high pollution and high energy consumption of construction enterprises, resulting in construction enterprises to go out.

Restricted by technology and management, as well as backward construction mode, coupled with the policy impact of Beijing, the outward orientation of the construction industry in Beijing, the capital, presents dynamic changes and keeps rising. From 2011 to 2018, Beijing's completed cross-provincial construction output value accounted for more than $60 \%$, and even more than $71 \%$ in 2018 , always ranking first.

Accelerating the pace of "going out," development is an urgent need for the construction industry to become larger and stronger. It is an inherent requirement for accelerating the replacement of old growth drivers with new ones and an important way to ensure and improve people's livelihood. The opportunity for Beijing to promote the distribution of noncapital functions reflects Beijing's efforts to control the "big city disease" and practice the sustainable development of the capital.

The environmental and social impacts of the businesses involved must be considered to develop the green economy and achieve the sustainable development of the construction industry [5]. The study of Hammad et al. [6] is the development planning of construction enterprise activities with the goal of minimizing the construction noise level. To promote the comprehensive, coordinated, and sustainable development of the modernization of China's regional construction industry, on the basis of the principle of industrial layout, Liu et al. [7] proposed countermeasures for the layout of the construction industry by analyzing the spatial layout of productivity.

The development of foreign construction industry pays more attention to the specification of Industry Foundation Classes (IFC) and the application of technology. Pauwels and Terkaj [8] found that increasing information management and information exchange applications in the construction industry rely on the development of Semantic Web technology. Geoffrey concluded from his study that as a typical demand-driven industry, the import of interregional construction industry is a geographical distribution dependent on resources. Chen et al. [9] proposed a systematic method to measure the energy efficiency of the regional construction industry based on DEA-DA model and analyzed the changing trend of the energy efficiency of the construction industry in different regions of China.

The current academic research on the development level of the construction industry mainly focuses on the regional differences in the development level of the construction industry and its influence mechanism [10]. Less attention is paid to the influence of the development level of the internal construction industry of the node city in the industrial cluster on other cities. Ma and Hao [11] considered the dynamic intervention method of government subsidies to maximize social welfare and analyzed the sources of system instability in each link and the influence of related parameters on system stability and profitability, ignoring whether the level of development is coordinated with the structure of outward orientation. The results showed that with the government's attention to environmental protection within a reasonable range, the chaos in the development of the construction industry can be controlled.

Social complex factors, such as regional policy, economic level, and industrial layout, play a decisive role in each stage of the complex system in the development of the construction industry. China largely ignores the regulations of the construction industry, and the lack of institutions makes incentives for the construction industry bring considerable financial burden to the Chinese government.

Zhang et al. [12] studied the impact of environmental regulation policies on the overall industrial transfer by constructing a spatial panel measurement model and found that environmental regulation policies have different impacts on the transfer of different pollution-intensive industries. By comparing and analyzing the optimal decision under the three game strategies of noncooperative game, cooperative game, and cost-sharing contract in the supply chain, Ma and Sun [13] and Bao et al. [14] found that the development of the construction industry is dependent on the reduction of carbon emissions and government subsidies.

Given the high development cost of construction industrialization, economically backward areas have difficulties in developing. Chinese scholars believe that the study on the change of regional construction development level and its influence mechanism is of great significance to the formulation of national coordinated development policies for the construction industry. Domestic researchers have measured the contribution of the construction industry to the economic growth of various provinces and cities from the perspectives of national economic accounting [15], the current structure of the construction industry [16], and construction industrialization. Results show that the regional economy and the development of the construction industry are mutually promoting [17].

On the basis of the projection pursuit model and data envelopment analysis model, Ji et al. [18] conducted a comprehensive evaluation study on the development level differences of regional prefabricated buildings from static and dynamic dimensions. Liu et al. [19] during 2015-2016 measured the development level of the construction industry using a time-series multi-indicator model. They found that the spillover effect of the construction industry is evident in Beijing and Tianjin and the eastern and southern coastal areas and that the amplitude of the gradient change among regions is different. Ma et al. [20] used social network analysis and found that industrial agglomeration affects the collaborative innovation of the construction industry 
alliance in the Beijing-Tianjin-Hebei region. From the perspective of spatial correlation, $\mathrm{Bu}$ et al. [21] and Yang et al. [22] revealed that the development of the construction industry in different regions generally presents a ladder distribution from east to west and from fast to slow using spatial metrology methods.

This study aims to measure the spatial and temporal structures of the construction industry in Beijing and its influencing factors. Panel data of cross-provincial output value of the construction industry in Beijing from 2011 to 2018 are used as data support for this study. On the basis of regional architectural elements, this study constructs a crossregional influence model and a collaborative coupling evaluation model of China's construction industry. By evaluating the outward orientation of the construction industry in Beijing, this study makes a deep study on the crossregional development status and evolution trend of the construction industry in China. Furthermore, correlation analysis is used to judge the factors that influence the study on the outward orientation of the construction industry in Beijing.

\section{Methods}

\subsection{Cross-Regional Influence Model of the Construction Industry considering Regional Economic Factors}

2.1.1. Connotation of Cross-Regional Influence of the Construction Industry. The cross-regional influence of the construction industry mainly includes two aspects: gravity and outward force. Gravity represents the mutual attraction of Beijing's construction output value and its cross-provincial construction output value. The outward force represents the radiation effect of the cross-regional completion of Beijing's building output value. The magnitude represents the strength of the intercity industry association.

2.1.2. Cross-Regional Influence Model of the Construction Industry. The influence model combines the dual characteristics of spatial and attribute data. It is a function that analyzes the degree of influence of one variable on other variables. This study uses the basic data of the construction output value completed across provinces in Beijing to study the influence of the construction industry in Beijing on the construction industry of other provinces and cities in China. The calculation model is as follows:

$$
Y_{a b}=K \frac{f_{a} f_{b}}{d_{a b}^{m}}, \quad(a=1, b=1, \ldots, 30),
$$

where $a$ represents Beijing, $b$ represents a province or province other than Beijing, $Y_{a b}$ is the influence degree of $a$ construction industry on $b$ construction industry, $K$ is the correction coefficient, $f_{a}$ and $f_{b}$ are the factor scores of the cross-regional influence of the construction industry, and $d_{a b}$ is the economic distance between $a$ and $b$.

(1) Determination of the associated weight parameter $K$ : due to the asymmetry of the gravity of construction industry development in different provinces, $K=f_{a}$ l $\left(f_{a}+f_{b}\right)$ was taken as the correction coefficient of the gravity intensity of $a$ to $b$ in the province.

(2) Determination of $f_{a}$ and $f_{b}$ : regional population and GDP are usually taken as key indicators by traditional gravity model to measure the spatial linkage intensity of regional industries, and there is a lack of comprehensive understanding of the development system of the construction industry. Therefore, based on the gravity model, this article first established a comprehensive evaluation system for the cross-regional influence development of the construction industry, including three dimensions of economic development, social development, and ecological development. The index system is shown in Table 1. The entropy value method was used to calculate the weight of each index [25]. The regional construction industry development was evaluated comprehensively, and the scores of regional industrial development are obtained.

\subsection{Coupling Evaluation Model considering Regional Economic Factors}

2.2.1. Synergetic Coupling Evaluation Model. Coupling is a measure of the correlation among multiple modules or indicators. It shows the synergy among internal parameters $[26,27]$. The specific steps of the coupling evaluation model [28] are as follows.

$$
X_{i j}^{\prime}=\frac{X_{i j}-X_{j, \min }}{X_{j, \max }-X_{j, \min }}
$$

where $X_{i j}^{\prime}$ is the value after the standardization of the regional economy, the total output value of the construction industry, the geographical distance, the industrial layout, and relevant policies. $X_{i j}$ is the original value of social complex element $j$ in year $i(i=2011,2012, \ldots ; j=5$ : regional economy, total output value of the construction industry, geographical distance, industrial layout, and relevant policies). $X_{j, \max }$ and $X_{j,}$ min represent the maximum and minimum values of social complex element $j$ from 2011 to 2018, respectively.

The coefficient of the variation method to obtain the weight coefficient $w_{j}$ of the social complex element $j$ in the evaluation system can be expressed as follows:

$$
w_{j}=\frac{v_{j}}{\sum_{j=1}^{m} v_{j}},
$$

where $v_{j}$ is the variation coefficient of social complex element $j$.

The cross-regional influence of Beijing's construction output value $X$ and the comprehensive index $Y$ of complex social factors can be expressed as follows:

$$
\begin{aligned}
F_{i j} & =w_{j} X_{i j}^{\prime}, \\
X(Y) & =\sum F_{i j} .
\end{aligned}
$$

where $X(Y)$ represents the composite index of index $j$. 
TABLE 1: Evaluation index system of cross-regional influence of construction industry.

\begin{tabular}{|c|c|c|c|}
\hline The target layer & The rule layer & The index layer & $\begin{array}{l}\text { The } \\
\text { weight }\end{array}$ \\
\hline \multirow{9}{*}{$\begin{array}{l}\text { Cross-regional influence of the construction } \\
\text { industry }\end{array}$} & \multirow{5}{*}{$\begin{array}{l}\text { The economic development } \\
{[23]}\end{array}$} & Total assets of construction enterprises & 0.107 \\
\hline & & Profit and tax rate of construction output value & 0.045 \\
\hline & & GDP per capita & 0.081 \\
\hline & & Per capita consumption capacity & 0.096 \\
\hline & & Proportion of construction industry & 0.112 \\
\hline & \multirow{3}{*}{ The social development [24] } & Employees in construction enterprises & 0.112 \\
\hline & & Quality project quantity & 0.092 \\
\hline & & Construction industry to undertake scale & 0.193 \\
\hline & The ecological development & $\begin{array}{l}\text { Energy consumption intensity of construction } \\
\text { industry }\end{array}$ & 0.078 \\
\hline
\end{tabular}

The schematic of the coupling evaluation model is shown in Figure 1.

The coupling evaluation model of the cross-regional influence of Beijing's building output value and the complex social factors is shown as follows:

$$
C=\left[\frac{X Y}{(X+Y)^{2}}\right]^{1 / 2},
$$

where $C$ represents the coupling degree, which varies in the interval of $[0,1]$.

The degree of coupling can only show the strength of each other's role. Thus, it cannot represent the coordination of the entire coupled system. Therefore, a model of coupling and coordination was constructed to help judge the degrees of coupling and coordination in the entire system. A model of coupling coordination was constructed [29-31] based on the analysis of the coupling degree to further analyze the influence of Beijing on the construction industry of 30 other provinces and cities in China and the coordination between the comprehensive development level of the construction industry of each province and city [32].

$$
\begin{aligned}
& D=\sqrt{\mathrm{CT}}, \\
& T=a X+b Y,
\end{aligned}
$$

where $D$ is the coupling coordination degree, $C$ is the coupling degree, and $T$ is the comprehensive coordination index of the cross-regional influence of Beijing's construction output value and the complex social elements of all provinces and cities. $a$ and $b$ represent undetermined coefficients, which reflect the importance of $X$ and $Y$, respectively, and $a+b=1$. In this study, the authors believed that the cross-regional influence of Beijing's construction output value is as important as the social complex factors; that is, $a=b=1 / 2$.

\section{Empirical Research}

3.1. Data Sources. The data came from the National Database of the National Bureau of Statistics of China and the Beijing Housing and Urban-Rural Development White Paper. To ensure the comparability of the impact, the correction coefficient is $K=f_{b} /\left(f_{a}+f_{b}\right)$.
On the basis of the evaluation index of the influence degree of the construction industry in Beijing from 2011 to 2018, the time and space distribution map of the influence of Beijing's construction industry was obtained using ArcGIS software [33].

\subsection{Result}

3.2.1. Analysis on the Temporal and Spatial Characteristics of the Cross-Regional Influence of Beijing's Construction Industry

(1) Temporal Dimension. The local contribution rate of Beijing's construction industry had dropped rapidly since 2012. The proportion of the completed output value of the local construction industry dropped from approximately $38 \%$ in $2011-2013$ to $32 \%$ in 2015 (Figure 2). The crossregional influence of Beijing's construction industry steadily increased, and the cross-regional output value of Beijing's construction industry exceeded 300 billion yuan. Moreover, the average share of the construction industry in 31 provinces in China exceeded 60\%.

(2) Spatial Dimension. The regions with the greatest crossregional influence in Beijing's construction industry concentrated in Guangdong, Hebei, Shandong, Sichuan, Jiangsu, Henan, and Guizhou. The contribution rate of accumulative industries was 50.4\%, and the regional average was above $5 \%$.

Northwest China has been weakly correlated for a long time, while Tianjin, Hebei, and Guangdong Province reside in strong correlation, forming a strong contrast (Figure 3 and Table 2). The influence of the construction industry in Northeast and North China showed a negative growth trend in 2011-2018. The trend of the overall influence of the construction industry in South China and Central China was increasing. Since 2014, the relevance of Guangdong's influence has been greatly improved, and the state of high relevance has been maintained for 5 years due to the radiation effect and its own market demand. Shanghai and Jiangsu were in a high-low-high development trend. The development situation of the Beijing-Tianjin-Hebei region was relatively special. Its influence dropped sharply in 2015-2016 and then rebounded to the state of high outward direction.

Table 2 shows the cross-regional influence of Beijing's construction industry. 


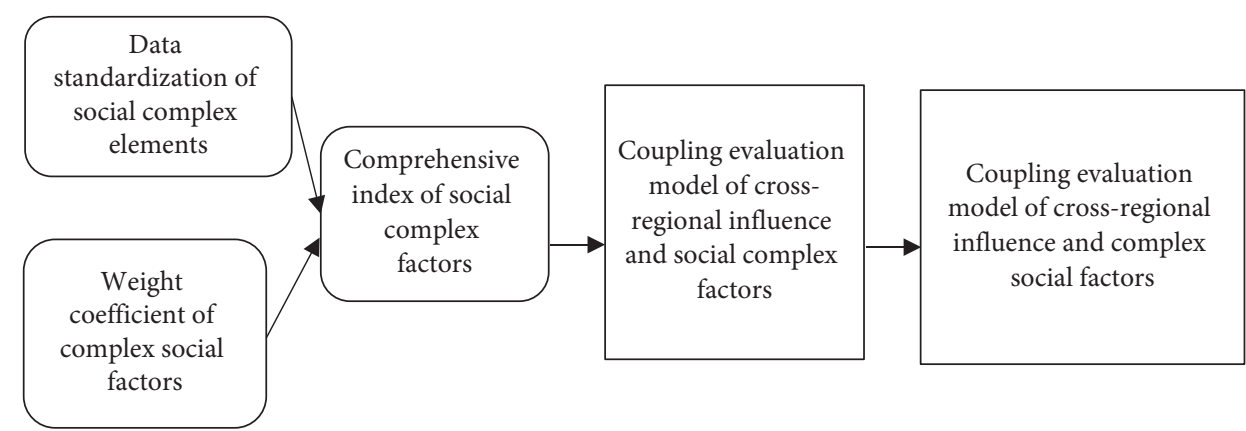

Figure 1: Schematic of coupling evaluation model.

(\%)

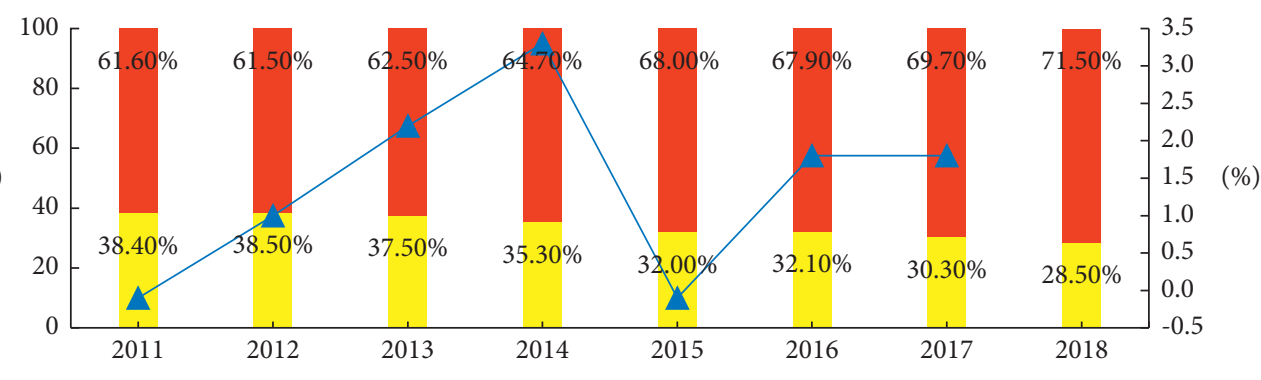

Percentage of construction output value completed in other provinces
- Percentage of construction output value completed in Beijing
- The outward growth rate of the construction industry

Figure 2: Proportion of the regional completion value in Beijing's construction industry from 2011 to 2018.

Among the cities with higher construction industry influence in Beijing are the core cities of the Beijing-TianjinHebei urban circle, except Guangdong. The following conclusions are drawn from the chart. From the perspective of spatial distribution, the correlation between the construction industry in Beijing and that in the northwest and northeast regions was slightly weaker than that in the eastern and southern coastal areas. From the perspective of the overall situation of the region, the degree of outward orientation was relatively obvious in the city classification from 2016 to 2018. Moreover, the degree of relevance between Guangdong Province and Beijing had overtaken Hebei Province and Tianjin City since 2014.

The total value of the construction industry in other regions, except Hebei Province, Tianjin City, Inner Mongolia Autonomous Region, and Liaoning Province, was gradually increasing (Figure 4). The construction output value of Inner Mongolia Autonomous Region and Liaoning Province had been decreasing annually, and its outward orientation with Beijing had been gradually becoming weakly correlated since 2014. The construction output value of Hebei Province exhibited a trough in 2015, and it strongly correlated with the outward orientation of Beijing's construction. This change had lasted until 2016 and then turned into a strong correlation.

Jiangsu Province, which is a major construction province, had continued to increase in construction output value, and it was in a generally related state with the outward orientation of Beijing's construction industry. Furthermore, alternating changes in general and weak correlations were observed in Shandong, Sichuan, and other places (Figure 5).

\subsubsection{Analysis of the Coupling between the Contribution} Value of Beijing's Construction Industry and Regional Construction Output Value. Based on the comprehensive evaluation index of the contribution value of Beijing's construction industry and corresponding regional construction output value from 2011 to 2018, ArcGIS software was used to classify the abovementioned indexes by natural breakpoint method.

The spatial differentiation diagram of the grade distribution and coupling degree of the contribution value of Beijing's construction industry and corresponding regional construction output value were obtained, as shown in Table 3 and Figures 6 and 7.

The average coupler of Chinese provinces (cities and autonomous regions) in 2011-2018 was between 0.32 and 0.51 , while all of them were at the level of the rival, except in 2015 (Figure 6). In 2015, the average coupling degree was at the peak state and reached the running-in degree. In 2016, the average coupling degree showed a slight decline. From 2016 to 2018, the development of the construction industry was lagging, the average index of regional total construction output remained low, and the coupling degree of the two was oscillating within the range of $0.35-0.32$, where the construction industry was in the state of rivaling. 

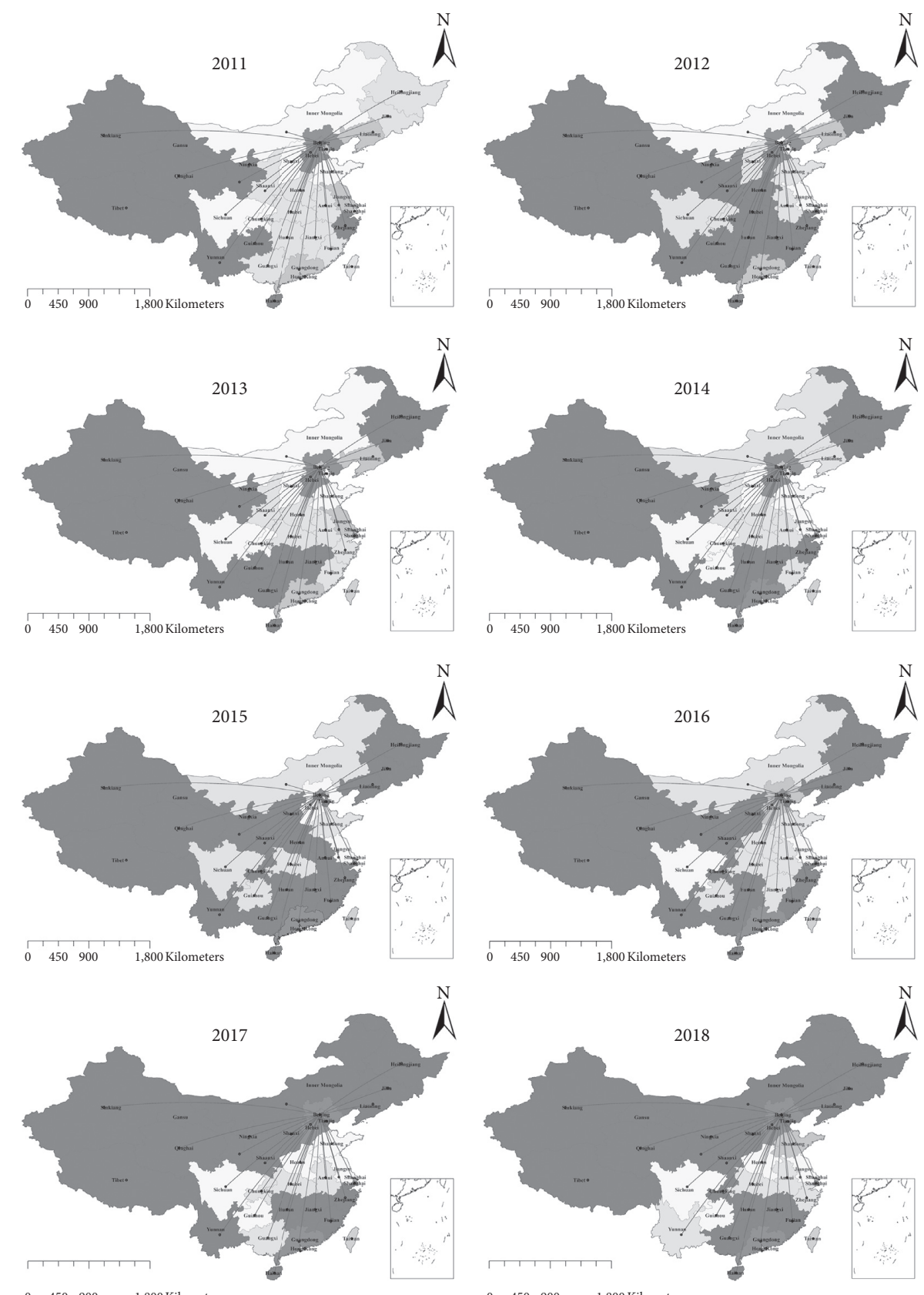

$0 \quad 450 \quad 900 \quad 1,800$ Kilometers

$\begin{array}{llll}0 & 450 & 900 & 1,800 \text { Kilometers }\end{array}$

FIGURE 3: Statistics of the influence degree of Beijing's construction industry.

The reason of development lag was closely related to the scale of the regional construction industry and the completion value of regional maturity. The output value of the regional construction industry was high, whereas the contribution rate of local construction output was low. Therefore, the development of the regional construction industry lagged. Conversely, the development of the regional construction industry and the economic level were relatively coordinated. The development of the construction industry was dominated by local areas.

Generally, the degree of connection with the outside world is high when the outward orientation of Beijing's construction industry is high. This situation can promote the development of the city's construction industry. If the urban construction demand capacity is high, then the city is closely connected with the outside world and can improve its outward orientation.

Because the strength of the interaction between the regional contribution value of Beijing's construction industry and the total regional construction output value, the general coupling process according to index size can be divided into low-level coupling, rivalry, running-in, and high-level coupling. When $0<\mathrm{C} \leq 0.3$, the province had less capacity to complete construction output value of the construction industry, and the construction output of the corresponding region was in low-level coupling. 
TABLE 2: Externality statistics of Beijing's construction industry.

\begin{tabular}{|c|c|c|c|c|c|c|c|c|}
\hline Province/year & 2011 & 2012 & 2013 & 2014 & 2015 & 2016 & 2017 & 2018 \\
\hline Heilongjiang & 0.013 & 0.010 & 0.012 & 0.013 & 0.014 & 0.015 & 0.016 & 0.010 \\
\hline Xinjiang & 0.008 & 0.008 & 0.011 & 0.009 & 0.007 & 0.008 & 0.013 & 0.009 \\
\hline Shanxi & 0.028 & 0.025 & 0.031 & 0.028 & 0.020 & 0.019 & 0.016 & 0.019 \\
\hline Ningxia & 0.007 & 0.005 & 0.005 & 0.006 & 0.004 & 0.006 & 0.009 & 0.005 \\
\hline Tibet & 0.001 & 0.001 & 0.001 & 0.002 & 0.001 & 0.002 & 0.002 & 0.004 \\
\hline Shandong & 0.023 & 0.024 & 0.031 & 0.034 & 0.031 & 0.031 & 0.045 & 0.053 \\
\hline Henan & 0.017 & 0.016 & 0.020 & 0.024 & 0.021 & 0.026 & 0.034 & 0.042 \\
\hline Jiangsu & 0.042 & 0.039 & 0.040 & 0.036 & 0.040 & 0.039 & 0.039 & 0.043 \\
\hline Anhui & 0.013 & 0.020 & 0.022 & 0.025 & 0.025 & 0.031 & 0.026 & 0.025 \\
\hline Hubei & 0.019 & 0.017 & 0.022 & 0.024 & 0.027 & 0.027 & 0.027 & 0.025 \\
\hline Zhejiang & 0.012 & 0.016 & 0.018 & 0.018 & 0.016 & 0.022 & 0.022 & 0.024 \\
\hline Jiangxi & 0.019 & 0.018 & 0.016 & 0.016 & 0.021 & 0.023 & 0.016 & 0.018 \\
\hline Hunan & 0.016 & 0.018 & 0.015 & 0.015 & 0.019 & 0.019 & 0.017 & 0.014 \\
\hline Yunnan & 0.010 & 0.008 & 0.012 & 0.015 & 0.020 & 0.017 & 0.019 & 0.026 \\
\hline Guizhou & 0.008 & 0.012 & 0.013 & 0.029 & 0.036 & 0.028 & 0.034 & 0.041 \\
\hline Fujian & 0.020 & 0.018 & 0.020 & 0.019 & 0.017 & 0.015 & 0.015 & 0.017 \\
\hline Guangxi & 0.016 & 0.017 & 0.015 & 0.016 & 0.020 & 0.021 & 0.024 & 0.023 \\
\hline Guangdong & 0.040 & 0.044 & 0.043 & 0.056 & 0.078 & 0.069 & 0.068 & 0.072 \\
\hline Hainan & 0.012 & 0.013 & 0.011 & 0.014 & 0.013 & 0.016 & 0.016 & 0.012 \\
\hline Jilin & 0.013 & 0.011 & 0.010 & 0.010 & 0.012 & 0.013 & 0.013 & 0.012 \\
\hline Liaoning & 0.038 & 0.044 & 0.037 & 0.025 & 0.024 & 0.022 & 0.016 & 0.012 \\
\hline Tianjin & 0.040 & 0.033 & 0.032 & 0.026 & 0.024 & 0.017 & 0.016 & 0.017 \\
\hline Qinghai & 0.007 & 0.007 & 0.007 & 0.007 & 0.007 & 0.006 & 0.005 & 0.004 \\
\hline Gansu & 0.011 & 0.010 & 0.011 & 0.011 & 0.008 & 0.013 & 0.012 & 0.010 \\
\hline Shanxi & 0.019 & 0.019 & 0.020 & 0.020 & 0.017 & 0.017 & 0.019 & 0.019 \\
\hline Inner Mongolia & 0.030 & 0.034 & 0.032 & 0.027 & 0.033 & 0.030 & 0.021 & 0.022 \\
\hline Chongqing & 0.023 & 0.024 & 0.029 & 0.029 & 0.025 & 0.020 & 0.025 & 0.019 \\
\hline Hebei & 0.071 & 0.061 & 0.053 & 0.049 & 0.050 & 0.051 & 0.061 & 0.063 \\
\hline Shanghai & 0.015 & 0.012 & 0.009 & 0.011 & 0.014 & 0.015 & 0.011 & 0.009 \\
\hline Sichuan & 0.028 & 0.025 & 0.027 & 0.031 & 0.033 & 0.041 & 0.039 & 0.047 \\
\hline
\end{tabular}

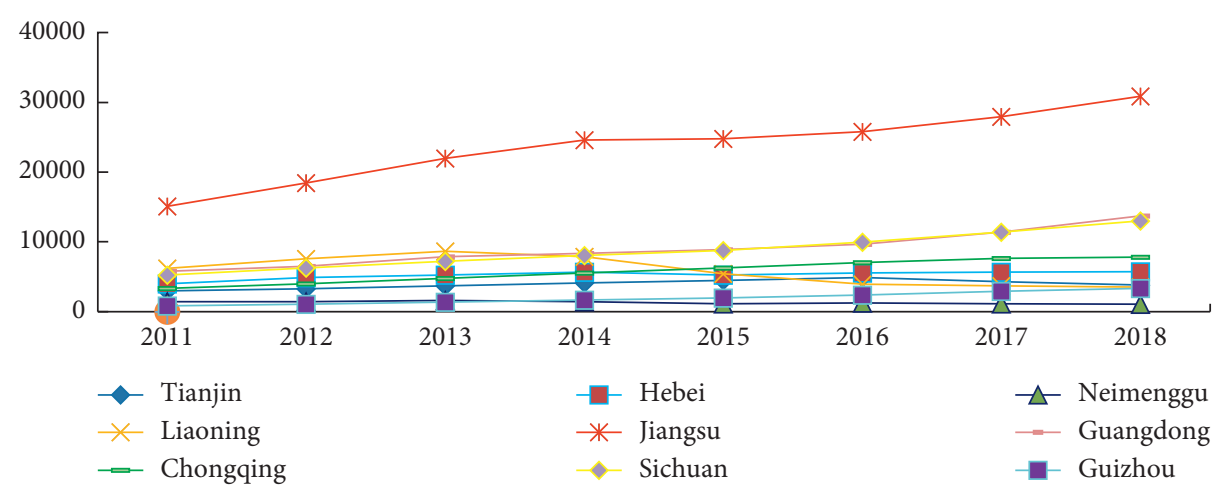

FIgURE 4: Changes in building output value in abnormal areas.

When $0.3<\mathrm{C} \leq 0.5$, the two areas were in the rivalry stage. When $0.5<\mathrm{C} \leq 0.8$, the two areas entered the running-in stage. When $0.8<\mathrm{C} \leq 1.0$, the two areas had high-level coupling.

Table 3 shows the coupling degree of the construction output value of 30 provinces, except Beijing. Most of China's provinces and cities are in low-level coupling and rivalry stage. In 8 years, the low-level coupling cities had increased from 11 to 13 , whereas the number of the rival cities had decreased from 17 to 13 . The cities in the running-in stage were Guangdong, Jiangsu, and Zhejiang (Figure 7).
3.2.3. Validation of Factors Affecting the Evolution of Beijing's Construction Industry. The evolution of the outgoing degree of the construction industry in Beijing was caused by many factors. The factors affecting the development of the construction industry are previously studied [7, 19, 34-37]; this study holds that policy support, supporting environment of the industry, and the development level of the regional construction industry are the macroeconomic factors that affect the change in the export-oriented degree of the construction industry.

To explore the factors influencing the degree of the outward orientation of Beijing's construction industry, 


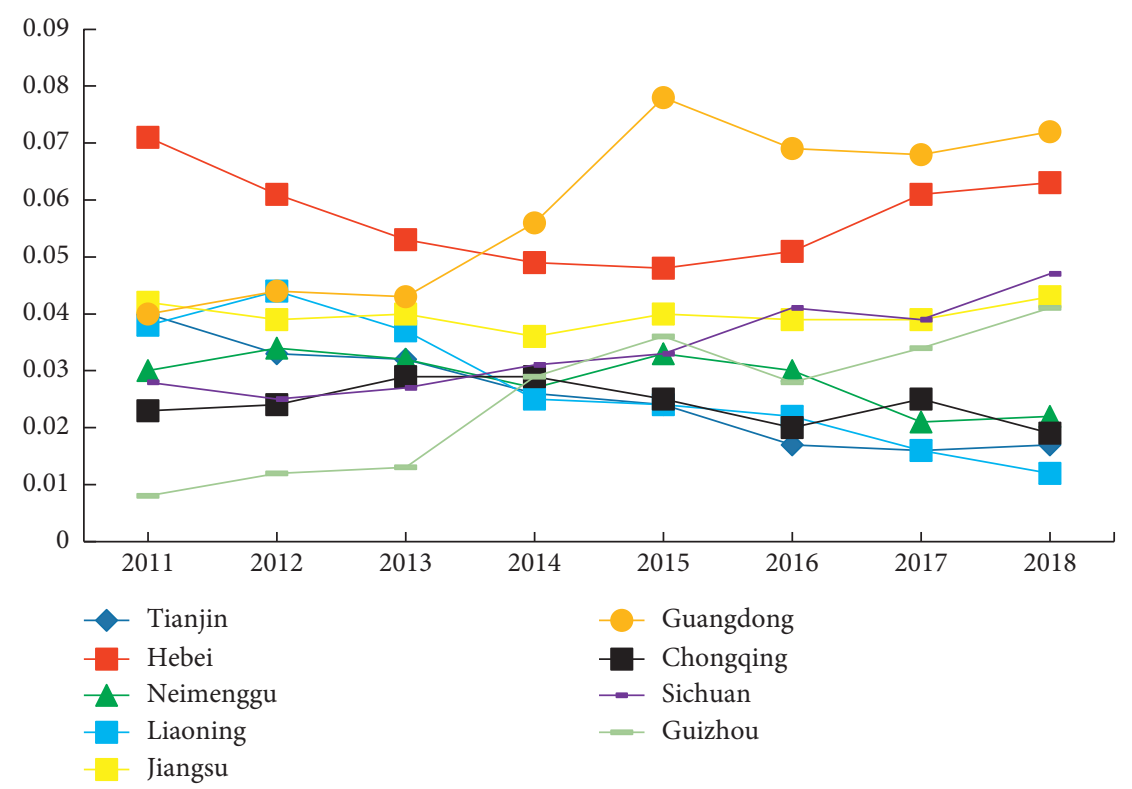

Figure 5: Fluctuation trend of influence degree of the construction industry in abnormal areas.

TABle 3: Coupling degree of the construction output value in 30 provinces of China (except Beijing).

\begin{tabular}{|c|c|c|c|c|c|c|c|c|}
\hline & 2011 & 2012 & 2013 & 2014 & 2015 & 2016 & 2017 & 2018 \\
\hline Tianjin & 0.40 & 0.39 & 0.39 & 0.38 & 0.38 & 0.35 & 0.31 & 0.28 \\
\hline Hebei & 0.50 & 0.51 & 0.49 & 0.49 & 0.48 & 0.48 & 0.47 & 0.46 \\
\hline Shanxi & 0.35 & 0.35 & 0.37 & 0.36 & 0.32 & 0.32 & 0.29 & 0.30 \\
\hline Inner Mongolia & 0.31 & 0.32 & 0.32 & 0.29 & 0.29 & 0.28 & 0.23 & 0.22 \\
\hline Liaoning & 0.48 & 0.52 & 0.51 & 0.44 & 0.40 & 0.35 & 0.29 & 0.24 \\
\hline Jilin & 0.26 & 0.26 & 0.26 & 0.26 & 0.26 & 0.26 & 0.24 & 0.21 \\
\hline Heilongjiang & 0.27 & 0.27 & 0.27 & 0.27 & 0.25 & 0.25 & 0.23 & 0.17 \\
\hline Shanghai & 0.35 & 0.33 & 0.30 & 0.32 & 0.35 & 0.35 & 0.31 & 0.26 \\
\hline Jiangsu & 0.62 & 0.63 & 0.66 & 0.65 & 0.67 & 0.66 & 0.63 & 0.64 \\
\hline Zhejiang & 0.45 & 0.49 & 0.52 & 0.53 & 0.52 & 0.56 & 0.54 & 0.53 \\
\hline Anhui & 0.32 & 0.36 & 0.39 & 0.41 & 0.41 & 0.43 & 0.39 & 0.39 \\
\hline Fujian & 0.36 & 0.36 & 0.38 & 0.39 & 0.40 & 0.38 & 0.37 & 0.38 \\
\hline Jiangxi & 0.31 & 0.32 & 0.33 & 0.33 & 0.37 & 0.38 & 0.33 & 0.34 \\
\hline Shandong & 0.43 & 0.44 & 0.48 & 0.51 & 0.49 & 0.49 & 0.52 & 0.54 \\
\hline Henan & 0.38 & 0.38 & 0.41 & 0.44 & 0.43 & 0.45 & 0.47 & 0.49 \\
\hline Hubei & 0.39 & 0.40 & 0.44 & 0.47 & 0.49 & 0.49 & 0.47 & 0.45 \\
\hline Hunan & 0.34 & 0.36 & 0.35 & 0.36 & 0.40 & 0.40 & 0.37 & 0.34 \\
\hline Guangdong & 0.48 & 0.50 & 0.52 & 0.56 & 0.61 & 0.60 & 0.58 & 0.60 \\
\hline Guangxi & 0.27 & 0.28 & 0.28 & 0.30 & 0.32 & 0.34 & 0.34 & 0.33 \\
\hline Hainan & 0.14 & 0.15 & 0.15 & 0.15 & 0.14 & 0.15 & 0.14 & 0.11 \\
\hline Chongqing & 0.36 & 0.38 & 0.41 & 0.42 & 0.42 & 0.40 & 0.40 & 0.36 \\
\hline Sichuan & 0.43 & 0.43 & 0.45 & 0.47 & 0.49 & 0.53 & 0.50 & 0.53 \\
\hline Guizhou & 0.19 & 0.22 & 0.24 & 0.31 & 0.34 & 0.33 & 0.34 & 0.36 \\
\hline Yunnan & 0.25 & 0.25 & 0.29 & 0.30 & 0.34 & 0.33 & 0.33 & 0.36 \\
\hline Tibet & 0.00 & 0.00 & 0.00 & 0.00 & 0.00 & 0.00 & 0.00 & 0.00 \\
\hline Shanxi & 0.33 & 0.35 & 0.36 & 0.36 & 0.35 & 0.35 & 0.35 & 0.34 \\
\hline Gansu & 0.21 & 0.23 & 0.24 & 0.24 & 0.22 & 0.25 & 0.22 & 0.19 \\
\hline Qinghai & 0.13 & 0.13 & 0.14 & 0.14 & 0.14 & 0.13 & 0.11 & 0.07 \\
\hline Ningxia & 0.15 & 0.14 & 0.14 & 0.15 & 0.13 & 0.14 & 0.14 & 0.07 \\
\hline Xinjiang & 0.22 & 0.22 & 0.26 & 0.24 & 0.22 & 0.22 & 0.25 & 0.18 \\
\hline
\end{tabular}

this study was based on the data of completed construction output value of Beijing in other provinces and used the influence model for analysis. Under the premise of the same development level of the local construction industry, the higher the regional contribution value of the construction industry in Beijing is, the stronger the outward orientation level of the city will be. However, influence analysis does not explain the factors that affect the outward orientation of the construction industry in Beijing. 


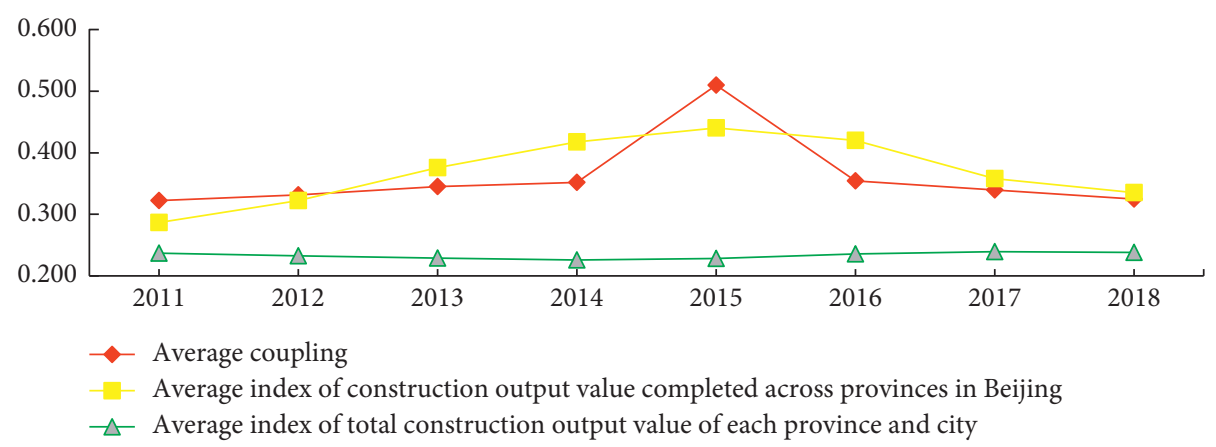

Figure 6: Average coupling degree of 30 provinces in China, average index of completed interprovince construction output in Beijing, and average index of regional construction output.
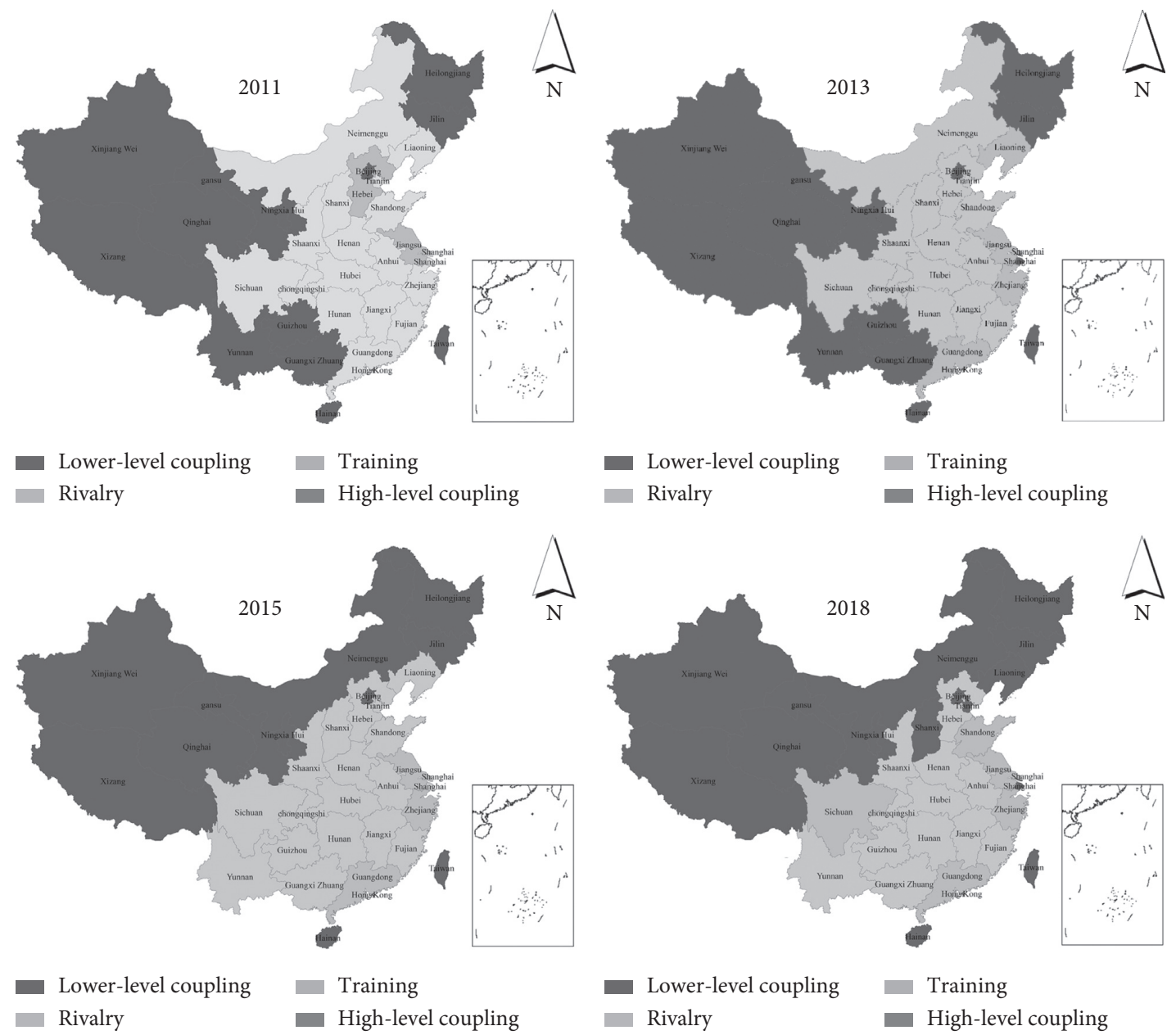

FIgURE 7: Distribution of coupling degree.

This study used the correlation analysis module of SPSS software. Through the analysis, the correlation coefficients between the regional contribution value of Beijing's construction industry in eight years (2011-2018) and the local financial expenditure/the total local financial expenditure of the construction industry, the output value of regional construction raw materials/the output value of the regional construction industry, and the total output value of the regional construction industry were obtained (Table 4).
The following conclusions can be drawn from the statistical data. A significant positive correlation existed between the contribution value of Beijing's construction industry and the supporting environment and the development level of the regional construction industry. A weak positive correlation also existed with policy support. In other words, this study analyzed the export-oriented degree of Beijing's construction industry from the perspective of the regional contribution value of the construction industry. The 
TABLE 4: Correlation coefficient table.

\begin{tabular}{|c|c|c|c|c|c|c|}
\hline \multirow{3}{*}{ Data properties } & \multirow{2}{*}{\multicolumn{2}{|c|}{$\begin{array}{l}\text { Industrial supporting environment } \\
\text { Output value of regional construction } \\
\text { raw materials/output value of regional } \\
\text { construction industry }\end{array}$}} & \multirow{2}{*}{\multicolumn{2}{|c|}{$\begin{array}{c}\text { Development level of regional } \\
\text { construction industry }\end{array}$}} & \multicolumn{2}{|c|}{ Policy support } \\
\hline & & & & & \multicolumn{2}{|c|}{$\begin{array}{l}\text { Total output value of regional } \\
\text { construction industry }\end{array}$} \\
\hline & Sig. (2-tailed) & Pearson's correlation & Sig. (2-tailed) & Pearson's correlation & Sig. (2-tailed) & Pearson's correlation \\
\hline Beijing & 0 & $0.980^{* *}$ & 0 & $0.892^{* *}$ & 0 & $0.396^{* *}$ \\
\hline
\end{tabular}

industrial supporting environment was more consistent with the development level of the current construction market. In a reasonable range, reasonable policy support and other means could improve the radiation effect of Beijing on the development of the construction industry in all provinces.

To study the export-oriented level of Beijing's construction industry, some other factors should be considered, such as resource endowment, knowledge spillover, space cost, and market factors. Regional policy, economic level, industrial layout, and other social complexity factors play a decisive role in each stage of the complex system in the development of the construction industry. Therefore, Beijing's construction industry at the export-oriented level is not a single factor. For other factors, this study would not repeat them. Table 4 shows the Pearson's correlation coefficient between the regional contribution value of Beijing's construction industry and the local financial expenditure/the total local financial expenditure, the output value of regional construction raw materials/the output value of the regional construction industry, and the total output value of the regional construction industry.

\section{Discussion}

Based on the data of the construction industry from 2011 to 2018, this study used the influence model to describe the spatial and temporal characteristics of the influence of Beijing on the construction industry of 30 provinces and cities in China. Synergistic coupling model was used to evaluate the coupling between the contribution of the construction industry in Beijing and the development level of the regional construction industry. This study used SPSS software to further verify and analyze the influencing factors of Beijing's construction industry's outward orientation. The contributions are as follows.

The contribution rate of Beijing to the construction industry of 30 provinces in China (cities and autonomous regions) had been steadily increasing. The speed of increase was far greater than that of the inward development of Beijing's construction industry from 2010 to 2018. In addition, the growth rate of the outward influence of Beijing's construction industry plummeted in 2015 as a turning point and then slowly rebounded, but its growth rate did not rise to the highest point. These results were due to complex social factors, such as the industrial layout of the secondary industry and the promulgation of construction industry-related policies. Large emission industries, such as building materials, had been increasingly eliminated by Beijing in the first year of the 13th Five-Year Plan period in 2015. Beijing cancelled the qualifications of 161 second- and third-level construction companies at one time in 2015. Many construction enterprises in Beijing were eliminated, affecting the output value completed by Beijing in the provinces, and construction enterprises should improve their core competitiveness through digital transformation, with the concept of sustainable development as an important support.

The discovery of geographical distribution of China showed that the contribution rate of Beijing to the construction industry in the eastern and southern coastal areas of China was significantly higher than that in the northwest and northeast of China, showing a "catch-up effect." Moreover, the contribution rate of Beijing to Tianjin City, Hebei Province, and Guangdong Province was significantly higher than that of other regions in China.

The high relevance of the contribution rate of Beijing's construction industry to Guangdong Province had been maintained for 5 years from 2014 to 2018. This situation was directly related to the successive introduction of policies, such as the 13th Five-Year Plan for Housing and UrbanRural Development in Guangdong Province and the New Urbanization Plan of Guangdong Province (2016-2020). Guangdong Province has been striving to transform its industrial development mode. The continuous expansion of the scale of the construction industry had made its total construction output value rank among the best. The position role of this province had also been significantly enhanced, which made the pulling effect more prominent. The contribution of Beijing to the construction industry in the Inner Mongolia Autonomous Region had been continuously dropping. This situation was directly related to the slowdown of its own development speed caused by the related policies of Inner Mongolia's construction industry since 2014. With the publishing of the Implementation Plan for Green Building Action in Inner Mongolia Autonomous Region (Office of the Interior (2014) No. 1), the total output value of the construction industry of Inner Mongolia Autonomous Region had experienced a negative growth and exceeded more than $10 \%$. Its construction area was approximately 80.534 million $\mathrm{m}^{2}$, which decreased by $8.9 \%$ compared with the last year. Therefore, China should give full play to the leading role of the government, actively promote the transformation and upgrading of industries and a new round of opening under the framework of the "Belt and Road" strategy, drive the continuous improvement of urbanization level and quality with industrial development, and further promote the integration of industries and cities in various regions and regional economic integration. 
The analysis of coupling degree presented a clear spatial distribution characteristic of "high in the east and low in the west" and a lower level at a comparable stage in coupling between the contribution rate of Beijing's construction industry and the development level of China's construction industry. Areas with low levels of coupling coordination were mainly concentrated in the western and northeastern regions of China. Overall, the central region was at the comparable stage, and the coastal areas had the highest coordination and coupling. The development between the contribution rate of Beijing's construction industry and the level of regional development is not synchronized, except for some coastal areas in the east and core circle cities, the degree of contribution of Beijing's construction industry in other provinces and cities is lagging behind the local development level, and the city has insufficient power for further development, which will hinder the development of the city in the long run.

The verification of the factors that influence the degree of outward orientation of the construction industry in Beijing indicated that the supporting environment of the industry had the greatest influence on the regional contribution value of the construction industry in Beijing. The influence of the regional construction industry development level followed closely. Both factors had a significant positive effect on it. The contribution of the policy support to the construction industry in Beijing had a weak positive correlation. As the capital of China, the degree of outward orientation of the construction industry in Beijing had generally exceeded the average level in China. However, from the perspective of the development level of the construction industry, the strong industrial pattern must still go through a long development stage.

In summary, with the development of China's economy and society, the social status of the construction industry has becoming increasingly important. In terms of promoting employment and urban and rural economic development, the construction industry has made outstanding contributions to China's social and economic development. On the development trend of today's construction industry, construction companies and government agencies must play their respective functions.

Based on the exploration of supply-side reform and the requirements of high-quality development, enterprises can actively explore two aspects. One is to improve the efficiency of all-factor allocation and develop the whole process of engineering consultation. Second is to improve the production efficiency [38] of the entire industry chain and develop a collaborative work model to achieve high-quality development under the guidance of "new infrastructure."

For the government, policy concerns should not only be placed on the Tianjin-Hebei region but also be farsighted. From the perspective of industrial development, the space for industrial upgrading and growth should be expanded to the central and western regions while driving the economy of Tianjin City and Hebei Province. Relevant government agencies should strengthen policy guidance and support while protecting the development of the local construction industry [39]. The guiding role of the government can promote the coordinated development of the construction industry in various regions to a certain extent.

\section{Data Availability}

In this study, available data are based on the construction output value completed across provinces in Beijing from 2011 to 2018, and the original data location is https://www. bjjl.org.cn/index.php?id=1372\&menu=31.

\section{Conflicts of Interest}

The authors declare that there are no conflicts of interest.

\section{Acknowledgments}

This work was supported by the Beijing Municipal Natural Science Foundation (No. 9202006) and the Excellent Talent Project of North China University of Technology in 2019 (No. 216051360020XN225/004). The authors gratefully acknowledge this funding.

\section{References}

[1] J. Hong, G. Q. Shen, S. Guo, F. Xue, and W. Zheng, "Energy use embodied in China's construction industry: a multi-regional input-output analysis," Renewable and Sustainable Energy Reviews, vol. 53, pp. 1303-1312, 2016.

[2] Y. Liu and Z. Qiao, "Research on the development of beijingtianjin-hebei construction industry based on collaboration," Journal of Beijing Jiaotong University (Social Science Edition), vol. 16, no. 04, pp. 30-37, 2017.

[3] L. Xue and Y. Chen, "Assessment of the impact of non-capital functions on Beijing's economic structure," Journal of Hebei University of Economics and Trade, vol. 41, no. 4, pp. 89-99, 2020.

[4] C. Tian and L. Wang, "The advantages, challenges and countermeasures of my country's construction industry in international market competition," Construction Economy, vol. 36, no. 09, pp. 15-19, 2015.

[5] J. Ma, Y. Hou, W. Yang, and Yi Tian, "A time-based pricing game in a competitive vehicle market regarding the intervention of carbon emission reduction," Energy Policy, vol. 142, Article ID 111440, 2020.

[6] A. W. A. Hammad, A. Akbarnezhad, and D. Rey, "A multiobjective mixed integer nonlinear programming model for construction site layout planning to minimise noise pollution and transport costs," Automation in Construction, vol. 61, pp. 73-85, 2016.

[7] P. Liu, Q. Li, and H. Li, "Research on the development strategy of regional construction industry modernization: taking Jiangsu as an example," Construction Economy, vol. 40, no. 04, pp. 93-96, 2019.

[8] P. Pauwels and W. Terkaj, "EXPRESS to OWL for construction industry: towards a recommendable and usable ifcOWL ontology," Automation in Construction, vol. 63, pp. 100-133, 2016.

[9] Y. Chen, B. Liu, Y. Shen, and X. Wang, "The energy efficiency of China's regional construction industry based on the threestage DEA model and the DEA-DA model," KSCE Journal of Civil Engineering, vol. 20, no. 01, 2016.

[10] Y. Dai and C. Chen, "Spatial econometric analysis of regional differences in China's construction industry development," 
Statistics and Information Forum, vol. 25, no. 05, pp. 53-58, 2010.

[11] J. Ma and H. Ren, "Influence of government regulation on the stability of dual-channel recycling model based on customer expectation," Nonlinear Dynamics, vol. 94, no. 3, pp. 1775-1790, 2018.

[12] G. Zhang, W. Liu, and H. Duan, "Environmental regulation policies, local government enforcement and pollution-intensive industry transfer in China," Computers \& Industrial Engineering, vol. 148, Article ID 106748, 2020.

[13] J. Ma and L. Sun, "Complexity analysis about nonlinear mixed oligopolies game based on production cooperation," IEEE Transactions on Control Systems Technology, vol. 26, no. 04, pp. 1532-1539, 2018.

[14] B. Bao, J. Ma, and M. Goh, "Short- and long-term repeated game behaviours of two parallel supply chains based on government subsidy in the vehicle market," International Journal of Production Research, vol. 58, pp. 1-24, 2020.

[15] Zhejiang Gongshang University Research Group, "Analysis of the structural changes of the construction industry and its relevance to economic development," Survey the World, vol. 1, pp. 34-37, 2016.

[16] X. Tong, T. Zou, and Y. Tong, "Study on the spatial agglomeration of construction industry in jiangxi province based on the analysis of location gini coefficient," Science and Technology Management Research, vol. 32, no. 07, pp. 187190, 2012.

[17] X. Ma and X. Long, "An empirical analysis of the relationship between the construction industry and China's economic development," China's Collective Economy, vol. 1, no. 34, pp. 22-23, 2016.

[18] Y. Ji, Z. Duan, L. Zhao, and Q. Zhang, "Analysis of comprehensive differences in regional development level of Chinese prefabricated buildings_- based on PP-dea model," Science and Technology Management Research, vol. 39, no. 09, pp. 233-240, 2019.

[19] B. Liu, X. Chen, B. Xue, N. Fang, S. O. Management, and T. University, "Research on gradient changes and influential mechanism of development level in Chinese regional construction industry," Operations Research and Management Science, vol. 25, no. 01, pp. 254-261, 2016.

[20] H. Ma, S. Wang, and M. Huang, "Analysis of influencing factors of collaborative innovation of construction industry alliance based on social network analysis: taking the beijingtianjin-hebei region as an example," Science and Technology Management Research, vol. 38, no. 15, pp. 170-176, 2018.

[21] W. Bu, W. Zhou, and W. Li, "Research on the correlation of inter-provincial construction industry development based on factor Analysis," Chinese Journal of Civil Engineering and Management, vol. 36, no. 02, pp. 127-131+145, 2019.

[22] D. Yang, D. Chen, H. Li, J. Zhang, Y. Chen, and F. Li, "Research on the evaluation of the development level and change trend of my country's regional construction industry," Construction Economy, vol. 39, no. 05, pp. 16-20, 2018.

[23] Z. Wei, "Research on the impact of real estate industry on economic growth from the perspective of national economic accounting: taking sichuan as an example," Southwest Finance, vol. 9, pp. 38-40, 2013.

[24] Y. Dai, "Research on the coupling and coordination mechanism of construction industry and regional economic growth," Economics and Management, vol. 26, no. 7, pp. 80-84, 2012.

[25] Z. Li, S. Liu, X. Wang, M. Li, Q. Fan, and Y. Gao, “The impact of industrialization of beijing-tianjin-hebei prefabricated buildings on economic construction," Shanxi Architecture, vol. 45, no. 1, pp. 245-246, 2019.

[26] A. Sun, J. Wu, G. Liu, and J. Pang, "Analysis of the coupling degree of transportation and urbanization: taking Jiangsu province as an example," Urban Transportation, vol. 05, no. 02, pp. 42-46, 2007.

[27] Y. Li, H. Liu, Y. Fang, and J. Li, "Research on the coupling coordination mechanism between industrial water resources utilization and urbanization in the yangtze river economic belt of hunan province," Green Technology, vol. 04, pp. 208214, 2020.

[28] G. Li, "Research on the coupling and coordination development of industrial agglomeration and regional innovation capability," Statistics \& Decisions, vol. 34, no. 08, pp. 145-148, 2018.

[29] J. Huang and C. Fang, "Urbanization and ecological environment interactive coupling mechanism and regularity analysis," Geographical Research, vol. 02, pp. 211-220, 2003.

[30] P. Sun and C. Xiu, "Evaluation of the coupling degree of the human-land coupling system of mining cities from the perspective of vulnerability: taking fuxin city as an example," Regional Research and Development, vol. 29, no. 06, pp. 75-79, 2010.

[31] H. Liu, J. Li, Y. Li, and Y. Fang, "Study on the coupling and coordination mechanism of industrial structure and water resources utilization in hunan yangtze river economic zone," Journal of Natural Science of Hunan Normal University, vol. 43 , no. 02 , pp. $1-8,2020$.

[32] A. Sun, W. U. Jun, G. Liu, and A. P. Jinliang, "The study of coupling degree between traffic and urbanization: a case study of Jiangsu province," Urban Transport of China, vol. 02, pp. 42-46, 2007.

[33] M. Zhang, D. Y. Qiao, and Y. A. Dai, "A spatial econometric analysis of the construction's differences in China's provincial regions," Scientific Decision Making, vol. 03, pp. 87-93, 2010.

[34] L. Zhao, Q. Zhang, Y. Ji, and Z. Duan, "Evaluation of the regional development level of China's prefabricated construction industry," Journal of Civil Engineering and Management, vol. 36, no. 01, pp. 59-65, 2019.

[35] J. Bian, Z. Wang, and X. Liu, "Research on the restrictive factors of the development of prefabricated buildings based on principal component analysis," Construction Economy, vol. 42, no. 02, pp. 76-80, 2021.

[36] L. Li, "Study on the spatial differences and influencing factors of the development level of prefabricated buildings," Science and Technology Management Research, vol. 40, no. 22, pp. 196-205, 2020.

[37] G. Liu, D. Yang, and M. Liu, "Study on the development path of construction industry modernization: taking liaoning province as an example," Construction Economy, vol. 39, no. 02, pp. 14-17, 2018.

[38] X. Chen, "Study on the difference and spatial convergence of production efficiency changes in China's regional construction industry," Scientific Research Management, vol. 36, no. 11, pp. 148-154, 2015.

[39] T. Luo, X. Xue, Y. Wang, W. Xue, and Y. Tan, "A systematic overview of prefabricated construction policies in China," Journal of Cleaner Production, vol. 280, pp. 100-133, 2021. 